\title{
The Inability of Spotted Lanternfly (Lycorma delicatula) to Vector a Plant Pathogen between Its Preferred Host, Ailanthus altissima, in a Laboratory Setting
}

\author{
Rachel K. Brooks 1,*, Ashley Toland ${ }^{2}$, Andrew C. Dechaine ${ }^{3}$, Thomas McAvoy ${ }^{3}$ (D) and \\ Scott Salom ${ }^{3}$ \\ 1 Forest Health and Resiliency Division, Washington Department of Natural Resources, \\ Olympia, WA 98504, USA \\ 2 Integrated Pest Prevention and Management Program, Oregon Department of Agriculture, \\ Salem, OR 97301, USA; ashleyat@vt.edu \\ 3 Department of Entomology, Virginia Tech, Blacksburg, VA 24061, USA; dechaine@vt.edu (A.C.D.); \\ tmcavoy@vt.edu (T.M.); salom@vt.edu (S.S.) \\ * Correspondence: rachelkbrooks@gmail.com
}

Received: 2 July 2020; Accepted: 7 August 2020; Published: 9 August 2020

Simple Summary: The invasive and accidently introduced insect, the spotted lanternfly, is spreading rapidly and becoming abundant in the mid-Atlantic region of the USA. Though this insect prefers to feed on the also invasive tree-of-heaven, its ability to feed on other native and crop plant species is concerning, and therefore eradication and control efforts are underway. These efforts include targeting the difficult to control tree-of-heaven for removal. Recently, researchers have found that a naturally occurring fungus effectively kills the tree-of-heaven and work towards making this fungus publically available is ongoing. Therefore, we tested whether the spotted lanternfly is capable of spreading the pathogen between symptomatic fungus-inoculated tree-of-heaven seedlings or plant material to healthy tree-of-heaven seedlings in a controlled laboratory setting. In these conditions, we found no evidence that this transmission occurred. This included monitoring the seedlings for symptoms and sampling the seedlings and the insects for the fungus. This lack of transmission may indicate that the spotted lanternfly cannot help spread this fungus to other tree-of-heaven.

\begin{abstract}
With the recent introduction of the non-native spotted lanternfly (Lycorma delicatula) to the USA, research and concern regarding this insect is increasing. Though L. delicatula is able to feed on many different plant species, its preference for the invasive tree-of-heaven (Ailanthus altissima) is apparent, especially during its later life stage. Therefore, management focused on A. altissima control to help limit $L$. delicatula establishment and population growth has become popular. Unfortunately, the control of A. altissima is difficult. Verticillium nonalfalfae, a naturally occurring vascular-wilt pathogen, has recently received attention as a potential biological control agent. Therefore, we studied if $L$. delicatula fourth instars or adults could vector $V$. nonalfalfae from infected A. altissima material to healthy $A$. altissima seedlings in a laboratory setting. We were unable to re-isolate $V$. nonalfalfae from the $45 \mathrm{~A}$. altissima seedlings or from the $225 \mathrm{~L}$. delicatula utilized in this experiment. We therefore, found no support that $L$. delicatula could effectively vector this pathogen between A. altissima in laboratory conditions. Since $L$. delicatula's ability to vector $V$. nonalfalfae has implications for the dissemination of both this beneficial biological control and other similar unwanted plant pathogens, future research is needed to confirm these findings in a field setting.
\end{abstract}

Keywords: Verticillium nonalfalfae; biological control; biopesticide; tree-of-heaven; invasive species management 


\section{Introduction}

The recent accidental introduction and rapid spread of the spotted lanternfly, Lycorma delicatula (White) (Hemiptera: Fulgoridae), from its native range in China to Pennsylvania, US is a cause of much concern [1-3]. With economic impacts that are just beginning to be understood, it is likely that this hard to control insect will negatively impact vineyards, orchards, ornamental plants, timber trees, and residential properties [4-7].

Lycorma delicatula, an aggressive phloem feeder, has a large host range of more than 70 plant species [5,6]. However, studies from South Korea and the US suggest that the non-native tree-of-heaven (Ailanthus altissima (Miller) Swingle) is its preferred host. This is especially apparent as L. delicatula's host range narrows during its later life stages [1,3-7]. The preference for A. altissima may be driven by the tree's high sugar content [4] and L. delicatula ability to sequester the tree's quassinoids to use as defense chemicals [7]. This relationship, and whether A. altissima is required for L. delicatula development, is the focus of ongoing research.

Similar to L. delicatula, A. altissima is native to China, has invaded much of the US, and causes a wide range of negative impacts [8]. Ailanthus altissima is difficult to control using mechanical and chemical methods $[9,10]$, and has therefore been the target of a variety of biological control efforts, such as the not-yet-released Chinese weevil Eucryptorrhynchus brandti (Harold) (Coleoptera: Curculionidae) [11,12]. More recently, a very promising naturally occurring fungus found killing A. altissima in Pennsylvania (Verticillium nonalfalfae Inderb. (formerly Verticillium albo-atrum Reinke and Berthold) has also been the subject of biological control [13-15]. Movement of this vascular wilt pathogen within a stand through functional root grafts is rapid and can result in the local mortality of hundreds of $A$. altissima trees per year $[15,16]$. Little is known about the spread of the fungus over longer distances between stands, despite the fact that $V$. nonalfalfae has been found killing A. altissima in three different states $[13,17,18]$.

Since insects have the potential to vector plant pathogens, they can influence the large-scale dissemination of both beneficial biological controls and harmful plant pathogens. With regards to $V$. nonalfalfae, E. brandti has previously been shown in laboratory settings to vector this pathogen between A. altissima [19], but no research regarding L. delicatula as a plant pathogen vector has yet been published. Since the later instars and adults of L. delicatula are thought to disperse long distances and prefer A. altissima as a host [2], L. delicatula could play a significant role in disseminating $V$. nonalfalfae between A. altissima stands. Confirming the ability of L. delicatula to vector this proposed biological control agent would help land managers better predict the consequences of L. delicatula invasion and manage $A$. altissima more effectively.

The objective of this research was to determine if $L$. delicatula fourth instar nymphs or adults could transfer $V$. nonalfalfae from symptomatic A. altissima tissues to healthy A. altissima seedlings in a laboratory setting. We hypothesized that L. delicatula would be able to act as an effective vector of $V$. nonalfalfae.

\section{Materials and Methods}

\subsection{Overview}

Overall, L. delicatula fourth instars or adults were allowed to feed for $48 \mathrm{~h}$ on either symptomatic of asymptomatic A. altissima plant material (either seedlings or logs) before being transferred to healthy A. altissima seedlings where they fed for $72 \mathrm{~h}$. These seedlings were then allowed to grow insect free for an additional 3 weeks before being assessed for Verticillium wilt-like symptoms and destructively sampled for $V$. nonalfalfae isolation. Additionally, at the conclusion of the second feeding period, L. delicatula were washed in sterile water and the wash water was plated to determine if any viable $V$. nonalfalfae was present on the outside of the insects (Figures 1 and 2). 


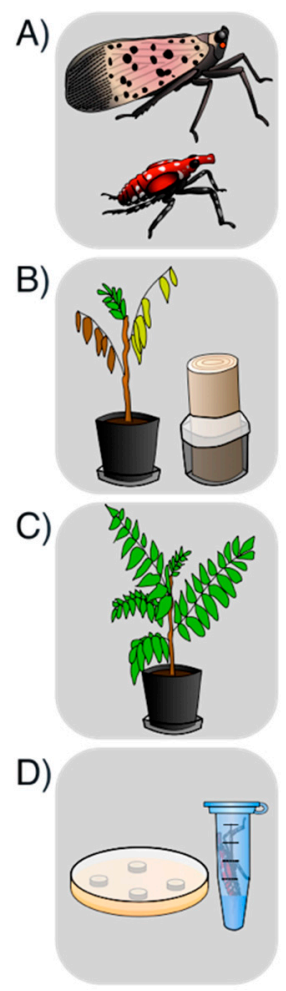

Figure 1. Experimental design illustrated. (A) Groups of 5 L. delicatula adults or fourth instars were field collected. (B) These groups of L. delicatula were then placed on A. altissima material (either seedlings or logs) that were either symptomatic or asymptomatic and allowed to feed for $48 \mathrm{~h}$. (C) These insects were then transferred to healthy non-inoculated seedlings to feed for $72 \mathrm{~h}$ before being removed. (D) Seedlings were allowed to grow for 3 more weeks before being assessed for symptoms and destructively sampled for $V$. nonalfalfae isolation, while the insects were immediately washed in sterile water that was then plated and monitored for $V$. nonalfalfae growth.

During the entirety of this research, all permit requirements were followed (Virginia Department of Agriculture and Consumer Services Office of Plant Industry Service Spotted Lanternfly Permit \# VASLF-19030 and USDA Animal and Plant Health Inspection Service, Plant Protection and Quarantine P526P-18-02138). Work conducted in the Beneficial Insects Containment Facility \#62 at the Virginia Tech Prices Fork Research Center, (4057 Prices Fork Road, Blacksburg, VA, USA, here after "Quarantine Lab") followed the facility's approved Standard Operating Procedure guidelines. In addition, any handling of plant material and insects that had been in contact with $V$. nonalfalfae was done using sterile techniques.

\subsection{Verticillium nonalfalfae Inoculum}

Cultures of Verticillium nonalfalfae VnAa200/NRRL66918 [18] were grown on prune extract agar amended with streptomycin sulfate and neomycin sulfate (PEA + SN) [20] starting in mid-May 2019. After 2-5 weeks of growth, sterile $0.1 \%$ peptone in water was used to suspend $V$. nonalfalfae conidia at $10^{7}$ conidia $\mathrm{mL}^{-1}$ for immediate use as an inoculum [14,15]. The germination rate of the inoculum was confirmed to be over $75 \%$ both before and after use by plating a subsample of the suspension on water agar and assessing germination after $24 \mathrm{~h}$.

\subsection{Ailanthus altissima Seedlng Source}

Ailanthus altissima seedlings were grown from seeds collected on 17 January 2019 in Blacksburg, VA and planted in trays filled with potting soil (Miracle-Gro ${ }^{\circledR}$ Potting Mix 0.21-0.11-0.16, ScottsMiracle-Gro, Marysville, OH, USA) on 29 January, 6 February, and 26 February 2019. Germinated seedlings were individually transferred to $3.8 \mathrm{~L}$ (1 gal) pots on 17 April 2019 and watered as needed. 


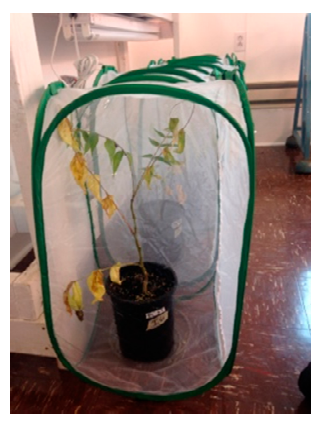

(a)

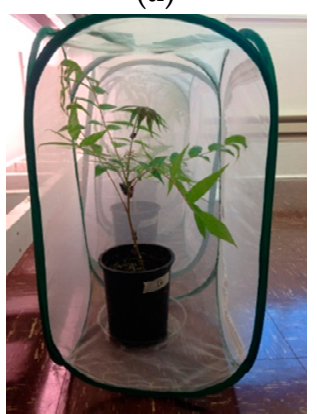

(c)

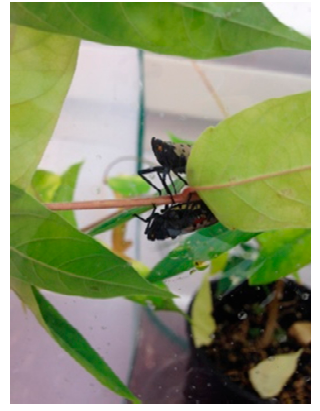

(e)

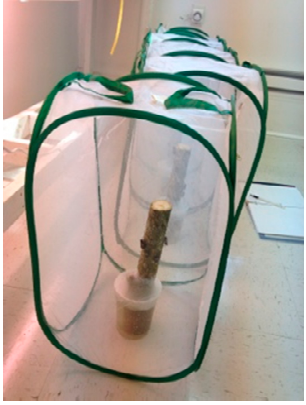

(b)

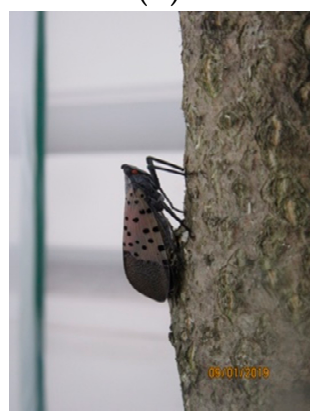

(d)

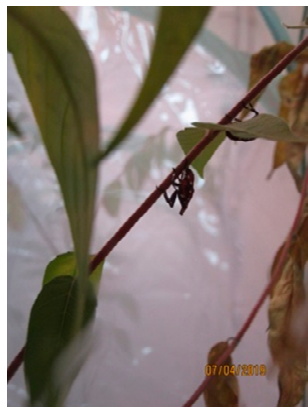

(f)

Figure 2. Images from the laboratory experiment: (a) Lycorma delicatula fourth instars feeding on a symptomatic seedling, (b) adults feeding on a healthy log, (c) adults feeding on a healthy seedling, (d) adult feeding on a symptomatic log, (e) adults feeding on a symptomatic seeding, and (f) fourth instars feeding on a symptomatic seedling.

To ensure that symptomatic and control seedlings would be present as needed throughout this experiment, these seedlings were inoculated with either $V$. nonalfalfae or a control on four different days (27 May, 5 June, 21 June, and 5 July 2019). At inoculation, a $0.1 \mathrm{~mL} \mathrm{~V}$. nonalfalfae inoculum or a sterile peptone and water control was inoculated into a seedling's xylem 1-2 cm above the soil line using a sterile syringe (SlipTip ${ }^{\mathrm{TM}} 0.5 \mathrm{~mm} \times 25 \mathrm{~mm}$ Insulin Syringe, Becton Dickinson and Co., Franklin Lakes, NJ, USA). Inoculated seedlings were kept at Virginia Tech's Washington Street Greenhouse (Blacksburg, VA, USA) and watered as needed. When required for the experiment, seedlings were transferred to the Quarantine Lab and placed on clean $20.3 \mathrm{~cm}$ (8 in) clear plastic saucers (Dotchi Garden ${ }^{\circledR}$, Miami, FL, USA) under grow lights at $25^{\circ} \mathrm{C}, 14$ light: 10 dark [19].

\subsection{Ailanthus altissima Mature Tree Source}

Mature trees were obtained from a 15-year old A. altissima stand that had regenerated within a previous clear-cut area at Virginia Tech's Shenandoah Valley Agricultural and Research Center in Raphine, VA. This regeneration stand contained patches of healthy A. altissima and symptomatic A. altissima artificially inoculated during a separate field experiment [21]. Ailanthus altissima trees selected for harvest were either asymptomatic and outside of symptomatic areas or symptomatic 
(majority of canopy symptomatic and xylem stained) and within previously $V$. nonalfalfae artificially inoculated areas. Ailanthus altissima were felled on 30 August 2019 and cut into $35 \pm 5 \mathrm{~cm}$ logs that ranged from 4 to $6 \mathrm{~cm}$ in diameter. The bottom of each log was then re-cut and immediately placed into separate $18.9 \mathrm{~L}$ ( 5 gallon) buckets containing $10 \mathrm{~cm}$ of water. When needed for the experiment, logs were removed from their buckets and placed individually into $0.95 \mathrm{~L}(32 \mathrm{oz})$ Deli Food Containers (Comfy Package) containing $5 \mathrm{~cm}$ of water and secured with Parafilm (Fisher, 13-374-10).

\subsection{Collecting L. delicatula}

Lycorma delicatula were field collected in Winchester, VA $(39.188,-78.131)$ when appropriate numbers of the desired life stages were reported. In total, at least 100 insects were collected during each collection event, allowing for a $25 \%$ mortality rate during transportation. Fourth instars were collected on 3 July 2019 and adults were collected on 25 July and 20 August 2019.

During field collections, groups of ten insects were placed into hard-plastic containers (Square PET Jars, General Bottle Supply, Los Angeles, CA, USA), which were then placed on ice in hard-plastic coolers secured with a ratchet strap. All insects were immediately brought back to the Quarantine Lab for immediate use.

\subsection{Exposing L. delicatula to Symptomatic Trees}

On the same day that each of the three L. delicatula field collections occurred, an experimental trial was initiated. To do this, five randomly chosen L. delicatula were placed into one of 15 pop-up mesh cages $34.3 \times 34.3 \times 61 \mathrm{~cm}\left(13.5 \times 13.5 \times 24^{\prime \prime}\right.$, BioQuip, $1466 \mathrm{BV}$, bleached and dried thoroughly before use). Ten of these mesh cages contained symptomatic $A$. altissima material while five contained asymptomatic $A$. altissima material. Fourth instars and the first set of adults collected were placed within symptomatic or asymptomatic potted seedling cages, while the second set of adults were exposed to logs collected from symptomatic or asymptomatic trees. The use of logs was included to account for adult $L$. delicatula's reported preference for feeding on woody plant tissues [3]. These insects were allowed to feed on the provided plant material for $48 \mathrm{~h}$, during which active feeding and insect survival was monitored at the 24 and $48 \mathrm{~h}$ marks. Active feeding was confirmed by visually observing each insect and recording the number whose stylet was inserted into the plant material.

After $48 \mathrm{~h}$ of feeding, all live insects were transferred into new pop-up mesh cages containing healthy non-inoculated A. altissima seedlings, and allowed to feed for $72 \mathrm{~h}$. The original A. altissima material was autoclaved and appropriately disposed of. Active feeding and survival were monitored at 24,48 , and $72 \mathrm{~h}$ after the insects were transferred. After $72 \mathrm{~h}$, all the insects were removed from these transfer seedlings.

\subsection{Culturing $V$. nonalfalfae from L. delicatula}

After removing L. delicatula from the feeding trial, each insect was individually placed into a sterile microcentrifuge tube $\left(1.5 \mathrm{~mL}\right.$ Fisherbrand ${ }^{\mathrm{TM}}$ for fourth instars or $5 \mathrm{~mL} \mathrm{MacroTube}^{\mathrm{TM}}$ for adults) containing $0.5 \mathrm{~mL}$ of sterile deionized (DI) water. These vials were vortexed for $30 \mathrm{~s}$ on high (NuAire, Inc. Plymouth, MN, USA), before the insects were removed using sterile tweezers and appropriately disposed of. The wash water was then plated on the Komada's agar $\left(500 \mathrm{~mL} \mathrm{H}_{2} \mathrm{O}\right.$, $1 \mathrm{~g}$ L-sorborose, $0.5 \mathrm{~g} \mathrm{~K}_{2} \mathrm{HPO}_{4}, 0.25 \mathrm{~g} \mathrm{KCl}, 0.25 \mathrm{~g} \mathrm{MgSO}_{4}, 0.0005 \mathrm{~g}$ EDTA, $1 \mathrm{~g}$ asparagine, $8.5 \mathrm{~g}$ plain agar, $0.5 \mathrm{~g} P C N B, 0.25 \mathrm{~g}$ oxgall, $0.5 \mathrm{~g} \mathrm{Na}_{2} \mathrm{~B}_{4} \mathrm{O}, 0.15 \mathrm{~g}$ streptomycin), a selective medium for isolating Verticillium spp. [22]. At the same time, a known $V$. nonalfalfae culture was streaked onto two control dishes also containing Komada's agar. All these dishes were stored in the dark at room temperature and checked for Verticillium-like growth after 7 and 14 days. Any Verticillium-like growth observed was transferred and monitored for whirl like conidiophores and the production of resting structures. If Verticillium was morphologically identified, species identification was confirmed using the molecular methods detailed in [23]. 


\subsection{Monitoring and Destructively Sampling A. altissima Seedlings}

After L. delicatula were removed from the final A. altissima seedlings, these seedlings were allowed to grow as needed for 21 days in the same laboratory conditions ( $25^{\circ} \mathrm{C}, 14$ light: 10 dark). They were then assessed for Verticillium wilt-like symptoms and destructively sampled at four locations on each seedling in which L. delicatula feeding had been observed (either on the stem or a specific petiole). Each of the areas selected for sampling were surface sterilized using $70 \% \mathrm{EtOH}$, cut to a $3 \mathrm{~mm}$ cross-section and plated on PEA+SN. Any discoloration of xylem observed was recorded and plated samples were monitored for Verticillium-like growth for 14 days. If Verticillium-like growth was observed, the potential $V$. nonalfalfae isolate was transferred to a new plate and morphologically and molecularly identified to species as described above. After these isolation attempts, all A. altissima materials were properly disposed of.

\subsection{Analysis}

The average difference in the number of $V$. nonalfalfae colonies re-isolated in wash water, the number of transfer seedlings displaying Verticillium wilt-like symptoms, the number of $V$. nonalfalfae colonies re-isolated from the transfer seedlings, the L. delicatula feeding rate (percent of live insects observed feeding at all observation periods within each cage), and L. delicatula survival (the percentage of all insects that survived the five-day experiment within each cage) during each of the three trials was compared using a permutation test run 1000 times. A two-sided $p$-value was calculated by totaling the number of times the absolute value of the null distribution difference of means were equal to or more extreme than the observed differences in means. Any $p$-values less than 0.05 were considered significant.

\section{Results}

\subsection{Culturing $V$. nonalfalfae from L. delicatula}

Wash water from 225 L. delicatula insects (75 fourth instars and 150 adults) was plated. Monitoring at 7 and 14 days after plating revealed no $V$. nonalfalfae-like growth, even though a positive $V$. nonalfalfae culture plated at the same time and kept in the same environment showed substantial $V$. nonalfalfae growth.

\subsection{Culturing $V$. nonalfalfae from A. altissima}

All 45 A. altissima seedlings (15 controls and $30 \mathrm{~V}$. nonalfalfae treatments) displayed no Verticillium wilt symptoms (leaflet wilt, leaflet chlorosis and necrosis, leaf drop, epicormic sprouting, or mortality) when assessed after three weeks. In addition, when all trees were destructively sampled no stained xylem was observed and no Verticillium-like growth was detected on the plated tissues.

\subsection{Active Feeding and Mortality}

Active feeding was observed within each cage of five insects on both initial and transfer plant material, with the percentage of live insects observed feeding at all observation periods for each cage ranging from $27-100 \%$ (Table 1). For each of the three trials the permutation test comparing treatment indicated that no significant difference in active feeding between treatments existed (Table 1). Though this was not significant, the average feeding was lower on insects exposed to symptomatic seedlings than those exposed to asymptomatic seedlings. This trend was not true for the logs.

At least one insect survived in each cage throughout the five-day experiment, with survival within each cage ranging from $20-100 \%$ (Table 1). There were no statistical treatment differences of survival. Though not significant, overall survival within cages provided with symptomatic A. altissima material was consistently lower numerically than those provided with asymptomatic A. altissima material. 
Table 1. The mean, standard deviation (SD), and sample size $(n)$ for the percent of live insects observed feeding at all observation periods within each cage (active feeding) and the percent of insects that survived the five-day experiment within each cage (survival). The $p$-values comparing the treatment effect for each trial calculated using a permutation test comparing means are reported for each trial pair.

\begin{tabular}{cccccccccccc}
\hline & & \multicolumn{4}{c}{ Active Feeding (\%) } & \multicolumn{5}{c}{ Survival (\%) } \\
\hline Life Stage & Type & Treatment & Mean & SD & $\boldsymbol{n}$ & $\boldsymbol{p}$ & Mean & SD & $\boldsymbol{n}$ & $\boldsymbol{p}$ \\
\hline fourth instar & seedling & control & 87.2 & 7.2 & 25 & \multirow{2}{*}{0.079} & 100 & 0.0 & 5 & \multirow{2}{*}{0.148} \\
fourth instar & seedling & V. nonalfalfae & 68.7 & 20.2 & 50 & & 74 & 32.7 & 10 & \\
adult & seedling & control & 90.4 & 7.8 & 25 & 0.194 & 100 & 0.0 & 5 & 1.000 \\
adult & seedling & V. nonalfalfae & 85.5 & 6.2 & 50 & & 98 & 6.3 & 10 & \\
adult & $\log$ & control & 87.2 & 15.1 & 25 & \multirow{2}{*}{1.000} & 100 & 0.0 & 5 & 0.519 \\
adult & $\log$ & V. nonalfalfae & 87.3 & 9.3 & 50 & & 94 & 9.7 & 10 & \\
\hline
\end{tabular}

\section{Discussion}

\subsection{Lycorma delicatula was Unable to Vector V. nonalfalfae between A. altissima in Laboratory Conditions}

We found no evidence that $L$. delicatula was able to vector $V$. nonalfalfae from symptomatic to healthy A. altissima. Since L. delicatula is a phloem feeder [2] it is possible that L. delicatula never feeds where $V$. nonalfalfae is found in the xylem. However, L. delicatula is known to probe [2], and therefore does have the potential to interact with the xylem. Additionally, electropenetrography (EPG) data for phloem feeding insects, though limited, indicates that xylem feeding is common [24], and has been shown to occur in Fulgoridae [25]. This inability of transferring $V$. nonalfalfae may indicate that $V$. nonalfalfae's large-scale dissemination might be better influenced by biopesticide applications from land managers, not natural dissemination by insects. Additionally, if L. delicatula is unable to vector a vascular wilt pathogen, it may indicate its inability to spread other unwanted plant pathogens.

We suspect that our results, though a first step in determining vector capabilities of L. delicatula, are inconclusive and additional research will be needed to fully understand L. delicatula's vector potential. For example, this experiment was conducted in a highly controlled laboratory environment in which we could ensure that replications were comparable and easily manage L. delicatula movement between cages. However, the laboratory conditions were not ideal for the shade intolerant $A$. altissima seedling growth for the extended length of time that these seedlings were monitored. If this experiment was repeated in a field setting using mature trees, not only would L. delicatula be provided with a higher quality food source and could be allowed to feed for longer periods of time, but the trees would remain vigorous for longer and, therefore, they could be better monitored for Verticillium wilt disease over much longer periods of time. Although $V$. nonalfalfae symptoms in the field and laboratory conditions typically become visible within 2-3 weeks [13], a smaller initial inoculum amount, such as one theoretically transferred by an insect vector, may extend the time needed to observe symptoms, therefore supporting the need for a longer-term field experiment.

While we did attempt to confirm the presence of viable $V$. nonalfalfae on the outside of L. delicatula, no attempt was made to determine if it was present within the insect. Circulative/propagative transmission of plant pathogens that colonize the vector body have been confirmed in numerous other systems, such as with the phloem-limited phytoplasmas that may be vectored by some Fulgoromorpha [26] and with the cotton fungal pathogen Ashbya gossypii [27]. Specific to this system, E. brandti was able to pass viable $V$. nonalfalfae propagules in their feces after feeding on infected A. altissima materials [19]. Though we did not test $L$. delicatula's honeydew or their internal tissues for $V$. nonalfalfae presence, our monitoring and destructive sampling of the A. altissima seedlings should have identified successful $V$. nonalfalfae transmission regardless of internal or external transmission. If successful transmission is observed in the future, a more detailed study of the location of $V$. nonalfalfae on L. delicatula should be completed.

Although we were able to sustain five insects within each cage over the five-day laboratory experiment, testing larger amounts of L. delicatula would likely increase the potential for $V$. nonalfalfae 
to be transferred. This is especially true since numbers of insects counted feeding on a single tree have tallied over 12,000 [13], and therefore if individual L. delicatula only rarely acted as a vector, large populations might more consistently transmit disease and more accurately represent L. delicatula's vector capabilities.

\subsection{Active Feeding Numbers Indicate Method Realistic}

Since active feeding was observed in each cage of five insects throughout this experiment, we believe this testing setup within a quarantine facility was effective. Even though there were no statistical differences of feeding rates between the control and $V$. nonalfalfae treated materials in these three trials, cages provided with symptomatic A. altissima seedlings tended to have lower feeding rates. Future research determining if $L$. delicatula preferentially fed on asymptomatic or symptomatic seedlings would also help us to better understand the relationship between these three organisms, as effective plant pathogen vectors need to have a high association with diseased plants [28].

\subsection{Mortality Insignificant between Feeding Treatments}

Very high levels of survival were observed during this five-day experiment. This indicates that though L. delicatula are not easy to rear in laboratory conditions [3], they can be easily field collected and studied during short periods when their populations are abundant in the field.

Though not statistically different, no L. delicatula insects died when provided with healthy A. altissima material, while small portions of fourth instars and adults succumbed when initially provided with symptomatic A. altissima. This trend could have implications for L. delicatula to sustain a close association with diseased plants which is needed in order to be an effective plant pathogen vector [28].

\section{Conclusions}

We found no laboratory support for the ability of L. delicatula to vector $V$. nonalfalfae between symptomatic and healthy A. altissima. Further testing of L. delicatula's vector ability in the field would help confirm these results.

Author Contributions: Conceptualization, R.K.B. and S.S.; methodology, R.K.B., A.T., A.C.D., T.M., and S.S.; formal analysis, R.K.B.; resources, S.S.; data curation, R.K.B.; writing-original draft preparation, R.K.B.; writing-review and editing, R.K.B., A.T., A.C.D., T.M., and S.S.; visualization, R.K.B.; project administration, S.S.; funding acquisition, S.S. All authors have read and agreed to the published version of the manuscript.

Funding: This research was funded by Virginia Department of Forestry, Federal Flow Through Fund number 23046.

Acknowledgments: We would like to thank Abby Biggs, Laura Nixon, and Anton Baudoin for their assistance. We also wish to thank the two anonymous reviewers whose comments helped improve this manuscript.

Conflicts of Interest: The authors declare no conflict of interest. The funders had no role in the design of the study; in the collection, analyses, or interpretation of data; in the writing of the manuscript, or in the decision to publish the results.

\section{References}

1. Barringer, L.E.; Donovall, L.R.; Spichiger, S.E.; Lynch, D.; Henry, D. The First new world record of Lycorma delicatula (Insecta: Hemiptera: Fulgoridae). Entomol. News 2015, 25, 20-23. [CrossRef]

2. Lee, D.-H.; Park, Y.-L.; Leskey, T.C. A Review of biology and management of Lycorma delicatula (Hemiptera: Fulgoridae), an emerging global invasive species. J. Asia-Pac. Entomol. 2019, 22, 589-596. [CrossRef]

3. Urban, J.M. Perspective: Shedding light on spotted lanternfly impacts in the USA. Pest Mgmt. Sci. 2020, 76, 10-17. [CrossRef] [PubMed] 
4. Lee, J.-E.; Moon, S.-R.; Ahn, H.-G.; Cho, S.-R.; Yang, J.-O.; Yoon, C.-M.; Kim, G.-H. Feeding behavior of Lycorma delicatula (Hemiptera: Fulgoridae) and response on feeding stimulants of some plants. Korean J. Appl. Entomol. 2009, 48, 467-477. [CrossRef]

5. Kim, J.G.; Lee, E.H.; Seo, Y.M.; Kim, N.Y. Cyclic behavior of Lycorma delicatula (Insecta: Hemiptera: Fulgoridae) on host plants. J. Ins. Behav. 2011, 24, 423-435. [CrossRef]

6. Dara, S.K.; Barringer, L.; Arthurs, S.P. Lycorma delicatula (Hemiptera: Fulgoridae): A new invasive pest in the United States. J. Integr. Pest. Mgmt. 2015, 6, 20. [CrossRef]

7. Song, S.; Kim, S.; Kwon, S.W.; Lee, S.-I.; Jablonski, P.G. Defense sequestration associated with narrowing of diet and ontogenetic change to aposematic colours in the spotted lanternfly. Scient. Repts. 2018, 8, 1-11. [CrossRef]

8. Kowarik, I.; Säumel, I. Biological flora of Central Europe: Ailanthus altissima (Mill.) Swingle. Perspect. Plant Ecol. Evol. Syst. 2007, 8, 207-237. [CrossRef]

9. Asaro, C.; Becker, C.; Creighton, J. Control and Utilization of Tree-of-Heaven: A Guide for Virginia Landowners; No. P00144; Department of Forestry Publication: Charlottesville, VA, USA, 2009; p. 15.

10. Gover, A.; Johnson, J.; Lloyd, K.; Sellmer, J. Tree-of-heaven (Ailanthus altissima). In Quicksheet 5. Wildland Weed Management; Penn State, College of Agricultural Sciences: State College, PA, USA, 2013.

11. Herrick, N.J.; Salom, S.M.; Kok, L.T.; McAvoy, T.J. Life History, development, and rearing of Eucryptorrhynchus brandti (Coleoptera: Curculionidae) in quarantine. Ann. Entomol. Soc. Am. 2011, 104, 718-725. [CrossRef]

12. Herrick, N.J.; McAvoy, T.J.; Snyder, A.L.; Salom, S.M.; Kok, L.T. Host-range testing of Eucryptorrhynchus brandti (Coleoptera: Curculionidae), a candidate for biological control of tree-of-heaven, Ailanthus altissima. Environ. Entomol. 2012, 41, 118-124. [CrossRef]

13. Schall, M.J.; Davis, D.D. Ailanthus altissima wilt and mortality: Etiology. Plant Dis. 2009, 93, 747-751. [CrossRef] [PubMed]

14. O'Neal, E.S.; Davis, D.D. Biocontrol of Ailanthus altissima: Inoculation protocol and risk assessment for Verticillium nonalfalfae (Plectosphaerellaceae: Phyllachorales). Biocont. Sci. Tech. 2015, 25, 950-969. [CrossRef]

15. O'Neal, E.S.; Davis, D.D. Intraspecific root grafts and clonal growth within Ailanthus altissima stands influence Verticillium nonalfalfae transmission. Plant Dis. 2015, 99, 1070-1077. [CrossRef] [PubMed]

16. Kasson, M.T.; Short, D.P.; O’Neal, E.S.; Subbarao, K.V.; Davis, D.D. Comparative pathogenicity, biocontrol efficacy, and multilocus sequence typing of Verticillium nonalfalfae from the invasive Ailanthus altissima and other hosts. Phytopath 2014, 104, 282-292. [CrossRef]

17. Rebbeck, J.; Malone, M.A.; Short, D.P.G.; Kasson, M.T.; O'Neal, E.S.; Davis, D.D. First report of Verticillium wilt caused by Verticillium nonalfalfae on tree-of-heaven (Ailanthus altissima) in Ohio. Plant Dis. 2013, 97, 999. [CrossRef]

18. Snyder, A.L.; Kasson, M.T.; Salom, S.M.; Davis, D.D.; Griffin, G.J.; Kok, L.T. First report of Verticillium wilt of Ailanthus altissima in Virginia caused by Verticillium nonalfalfae. Plant Dis. 2013, 97, 837. [CrossRef]

19. Snyder, A.L.; Salom, S.M.; Kok, L.T.; Griffin, G.J.; Davis, D.D. Assessing Eucryptorrhynchus brandti (Coleoptera: Curculionidae) as a potential carrier for Verticillium nonalfalfae (Phyllachorales) from infected Ailanthus altissima. Biocont. Sci. Tech. 2012, 22, 1005-1019. [CrossRef]

20. Talboys, P.W. A culture-medium aiding the identification of Verticillium albo-atrum and V. dahliae. Plant Path. 1960, 9, 57-58. [CrossRef]

21. Brooks, R.K.; Wickert, K.L.; Baudoin, A.; Kasson, M.T.; Salom, S.M. Field-inoculated Ailanthus altissima stands reveal the biological control potential of Verticillium nonalfalfae in the mid-Atlantic region of the United States. Biol. Control. 2020, 148, 104298. [CrossRef]

22. Christen, A. A selective medium for isolating Verticillium albo-atrum from soil. Phytopathology 1982, 72, 47-49. [CrossRef]

23. Inderbitzin, P.; Davis, R.M.; Bostock, R.M.; Subbarao, K.V. Identification and differentiation of Verticillium species and V. longisporum lineages by simplex and multiplex PCR assays. PLoS ONE 2013, 8, e65990. [CrossRef] [PubMed]

24. Pompon, J.; Quiring, D.; Goyer, C.; Giordanengo, P.; Pelletier, Y. A phloem-sap feeder mixes phloem and xylem sap to regulate osmotic potential. J. Insect Physiol. 2011, 57, 1317-1322. [CrossRef] [PubMed]

25. Khan, Z.R.; Saxena, R.C. Technique for demonstrating phloem of xylem feeding by leafhoppers (Homoptera: Cicadellidae) and planthoppers (Homoptera: Delphacidae) in rice plant. J. Econ. Entomol. 1984, 77, 550-552. [CrossRef] 
26. Weintraub, P.G.; Beanland, L. Insect vectors of phytoplasmas. Rev. Entomol. 2006, 51, 91-111. [CrossRef]

27. Mitchell, P.L. Heteroptera as vectors of plant pathogens. Neotrop. Entomol. 2004, 33, 519-545. [CrossRef]

28. Leach, J.G. Insect Transmission of Plant Diseases; McGraw-Hill Book Co., Inc.: New York, NY, USA, 1940.

(C) 2020 by the authors. Licensee MDPI, Basel, Switzerland. This article is an open access article distributed under the terms and conditions of the Creative Commons Attribution (CC BY) license (http://creativecommons.org/licenses/by/4.0/). 